subsequent or second-line regimen would be Pl-based.

Any interested treaters who would like to participate should e-mail the managing editor of the Southern African Journal of HIV Medicine at Igbekker@cormack.uct.ac.za, expressing the number of patients likely to be treated at their site in the next year.

REFERENCES

Morcroft A, Vella S, Benfield Th et al. Changing mortality across Europe in patients infected with HIV-1. Lancet 1998; 352: 1725-1730.

2. Moore RD, Chaisson RE. Natural history of HIV infection in the era of combination antiretroviral therapy. AIDS 1999; 13: 1933-1942.

3. Palella FJ, Delaney KM, Moorman AC, et al. Declining morbidity and mortality among patients with advanced human immunodeficiency virus infection. $N$ Engl J Med $1998 ; 338: 853-860$

4. World Health Organisation. Scaling Up Antiretroviral Theropy in Resource-Limited
Settings: Guidelines for a Public Health Approach. Geneva: WHO, 2002.

5. Harries AD, Nyangulu DS, Hargreaves NJ, Kaluwa O, Salaniponi FM. Preventing antiretroviral anarchy in sub-Saharan Africa. Loncet 2001; 358: 410-414

6. Levi GC, Vitoria MA. Fighting against AIDS: The Brazilian experience. AIDS 2002; 16 : 2373-2383.

7. Farmer $P$, Leandre F, Mukheriee 15 , et ol. Community-based approaches to HV treatment in resource-poor settings. Lancet 2001; 358: 404-409.

8. Boulle A, Kenyon C, Skordis J, Wood R. Rationing HAART Part I: An exploration of the costs of a limited public sector antiretroviral treatment programme in South Africa. SAfr Med \2002; 92: 811-817.

9. Bredell Consensus Statement on the Imperative to Expand Access to Antiretroviral Medicines for Adults and Children with HIV/AIDS in South Africa. November 2001 Notional Treatment Congress Resource Document Number 12. Cape Town: Treatment Action Campaign

10. Report on the global HIV/AIDS epidemic. Joint United Nations Programme on HIVIAIDS (UNAIDS). Geneva: UNAIDS, July 2002

11. Egger $M$, May $M$, Chene $G$, et al. Prognosis of HIV-1-infected patients starting highly active antiretroviral therapy: a collaborative analysis of prospective studies Lancet 2002; 360: 119-129.

12. Southern African HIV Clinicians Society. Clinical Guidelines: Antiretroviral Therapy in Adults. June 2002 version. Southern African Journal of HIV Medicine 2002; July (Issue 8): 22-29.

\title{
GUIDELINES
}

\section{INFANT HIV DIAGNOSTIC GUIDELINES TO FACILITATE ADOPTION}

\author{
Gayle G Sherman, $M B B C h, D C H$ (SA), DTMEH, MMed (Haem) \\ Department of Molecular Medicine and Haematology, fohannesburg Hospital, National Health Laboratory Service and University of the \\ Witwatersrand, fohannesburg
}

South Africa is currently estimated to have 300000 HIVIAIDS orphans, and the figure is likely to increase to 2 million by 2015.' Facilitating adoption of children affected by HIV provides a highly effective strategy for addressing the HIVIAIDS orphan crisis, albeit on a very small scale. The legal and ethical issues surrounding HIV testing of abandoned children for the purposes of adoption are not addressed here.
The qualitative HIV polymerase chain reaction (PCR) test is highly specific for HIV infection, but sensitivity varies with the age of the infant. ${ }^{2}$ The PCR identifies approximately $50 \%$ of infected infants at or just after birth and $>95 \%$ at $3-6$ months of age..$^{23}$ More recent evidence suggests that HIV PCR tests performed at $\geq 1$ month of age have a sensitivity of $\geq 95 \%$ and specificity of $>99 \%{ }^{4}$ The Roche Amplicor Kit (Roche Molecular Systems, Somerville, NJ)

These guidelines were contributed to and are endorsed by:

Dr Ashraf H Coovadia

Department of Paediatrics, Coronation Hospital, and University of the Witwatersrand

Dr Mark F Cotton

Paediatric Infectious Disease Unit, Tygerberg Children's Hospital, University of Stellenbosch

Dr Glenda E Gray

Perinatal HIV Research Unit, Chris Hani-Baragwanath Hospital and University of the Witwatersrand

Professor Gregory D Hussey

School of Child and Adolescent Health, University of Cape Town

Dr Leon J Levin

Paediatrician in private practice

Dr Tammy M Meyers

Department of Paediatrics, Chris Hani-Baragwanath Hospital and University of the Witwatersrand

Professor Lynn Morris

AIDS Unit, National Institute for Communicable Diseases and University of the Witwatersrand

Dr Adrian J Puren

National Institute for Communicable Diseases and University of the Witwatersrand

Dr Wendy S Stevens

Department of Molecular Medicine and Haematology, National Health Laboratory Service and University of the Witwatersrand

Dr Lynne M Webber

Department of Medical Virology, University of Pretoria 
6 weeks of age

HIV ELISA to assess HIV exposure at birth (omit if the HIV ELISA of the mother is confirmed positive)

Qualitative HIV PCR if the HIV ELISA of the infant (or the mother) is reactive

3 months of age

Qualitative HIV PCR to confirm result of PCR at 6 weeks of age

Notes

1. Clinical examination to assess for stigmata of HIV infection should be performed at 6 weeks and 3 months of age. The 6 -week clinical examination, when stigmata of HIV infection may be less evident, is likely to be less helpful than the 3 -month examination.

2. At 6 weeks of age, blood should be taken for both HIV ELSA and PCR tests and the PCR analysed only if the HIV ELISA test result is reactive.

3. Postnatal transmission of HIV infection is likely to be evident by 6 weeks after termination of breast-feeding; nevertheless it is recommended that the final qualitative HIV PCR test be performed 3 months after breast-feeding has ceased.

Interpretation

Two concordant qualitative HIV PCR results in an appropriate clinical context confirm the HIV status of the child.

Discrepant PCR results require further investigation.

version 1.5, which has shown excellent sensitivity and specificity in the South African setting, is the recommended qualitative (DNA) PCR test.

There are no published HIV diagnostic guidelines for facilitating adoption. Such guidelines require a balance between making an accurate diagnosis of the child's HIV infection status and doing so as early in life as possible, factoring in practicalities and cost considerations.

Current HIV diagnostic guidelines for perinatally exposed infants recommend that HIV infection be confirmed by 2 positive HIV PCR tests performed on different samples. Negative HIV infection status is established if 2 HIV PCR tests, the first at $\geq 1$ month of age and the second at $\geq 4$ months, are negative in a non-breast-fed infant. To determine definitively that the child is not infected, seroreversion should be demonstrated by 2 negative HIV enzyme-linked immunosorbent assay (ELISA) tests, the final one performed at 24 months of age. ${ }^{3.5}$

The second PCR test is done to confirm the first PCR result and to guard against technical or sample mix-up errors. This could be achieved by re-testing as soon as possible after the first PCR test result is known, ${ }^{23}$ but performing the second PCR at an older age increases the sensitivity of the test by detecting the $<5 \%$ of infants who will test positive for the first time after 1 month of age. The recommended HIV diagnostic protocol for adoption purposes is explained in the box above.

The possibility that antiretroviral therapy used in prevention of mother-to-child transmission (PMTCT) programmes may affect the timing of the PCR testing in infancy has not been substantiated." Local data on clinical stigmata of HIV at 6 weeks and 3 months of age and the sensitivity and specificity of qualitative HIV PCR as well as the influence of nevirapine for PMTCT on the timing of PCR testing are expected shortly. These diagnostic guidelines are likely to evolve as new data and technical improvements in testing become available. ${ }^{2}$
All abandoned neonates estimated to be $\leq 72$ hours of age should be given post-exposure prophylaxis. If logistics are in place for obtaining HIV test results quickly, only HIVexposed neonates should be treated.

It is theoretically possible for an HIV-exposed child to have a non-reactive HIV ELISA if the mother seroconverted late in pregnancy or, less plausibly, if she was terminally ill towards the end of the pregnancy. Both situations are associated with a high viral load and increased propensity for vertical transmission of HIV. The suggested diagnostic guidelines would not detect neonates exposed to HIV under these circumstances unless they presented with clinical stigmata. Despite the high prevalence of HIV in South Africa, it is expected to be rare for an HIV-exposed child to have a non-reactive HIV ELISA test, so qualitative HIV PCR testing of every child being investigated for adoption is not warranted.

Adoptive parents need to be aware of the fact that despite comprehensive general medical examinations and testing, there is no guarantee of a completely healthy child. In the context of HIV testing, this applies to the possibility of a negative HIV ELISA in an HIV-exposed child, as well as the recommendation to do the final HIV PCR test at 3 months instead of the exceptionally expensive and extreme recommendation of an HIV ELISA at 24 months of age. ${ }^{24.5}$ Performing additional HIV tests is unlikely to yield different results from those achieved using the diagnostic guidelines suggested above.

\section{REFERENCES}

Johnson L, Dorrington R. The impact of AIDS on orphanhood in South Africa: A quantitative analysis. Centre for Actuarial Research: Monograph No. 4. 2001. ISBN 0799220892

www.commerce.uct.ac.za/care/Monographs/Monographs/mono04.pdf laccessed 22 May 2003).

2. Working Group on Antiretroviral Therapy: National Pediatric HIV Resource Center. Antiretroviral therapy and medical management of the human immunodeficiency virus-infected child. Pediatr Infect Dis J 1993; 12: 513-522.

3. Centers for Disease Control. 1995 Revised Guidelines for Prophylaxis Against Pneumocystis carinii Pneumonia for Children Infected With or Perinatally Exposed To Human immunodeficiency Virus. MMWR Morbid Mortal Wkly Rep 1995 44(RR-4): 1-11.

4. Benjamin DK, Miller WC, Fiscus SA, et al. Rational testing of the HIV-exposed infant Peciatrios 2001; 108(1): e3.

5. American Academy of Pediatrics. Evaluation and medical treatment of the HIVexposed infant Fediotrics 1997; 99(6): 909-917. 